Курский государственный университет, г. Курск, Российская Федерация

\title{
ПСИХОЛОГО-ПЕДАГОГИЧЕСКОЕ СОПРОВОЖДЕНИЕ СЕМЕЙ, ВОСПИТЫВАЮЩИХ ДЕТЕЙ С ЗАДЕРЖКОЙ ПСИХИЧЕСКОГО РАЗВИТИЯ ДОШКОЛЬНОГО ВОЗРАСТА
}

\begin{abstract}
АНнОТАЦия. В исследовании отражаются результаты анализа психолого-педагогической литературы по вопросу психолого-педагогического сопровождения семей, воспитывающих детей с задержкой психического развития дошкольного возраста. Отмечается актуальность заявленной проблемы в связи с увеличением количества детей с задержкой психического развития и неспособностью родителей выстраивать отношения собственными детьми. Определяется спектр проблем, с которыми сталкиваются родители, воспитывающие детей с задержкой психического развития дошкольного возраста. Рассматриваются подходы к осуществлению психолого-педагогического сопровождения семей, воспитывающих ребенка с задержкой психического развития дошкольного возраста. Описываются особенности детско-родительских отношений в семьях, воспитывающих ребенка с задержкой психического развития. Дается характеристика результатов диагностики детско-родительских отношений, систематизированы общие, особенные и единичные проблемы детско-родительских отношений в семьях, воспитывающих ребенка с задержкой психического развития дошкольного возраста. Определяются основные направления работы школьного педагога-психолога по осуществлению психолого-педагогического сопровождения семьи, воспитывающей ребенка с задержкой психического развития дошкольного возраста. Представлен проект программы психолого-педагогического сопровождения семьи, воспитывающей ребенка с задержкой психического развития дошкольного возраста.

кЛЮчЕВЫЕ СЛОВА. Психолого-Педагогическое сопровождение; семья; ребенок с задержкой психического развития; направления работы школьного педагога-психолога.

ИНФОРМАЦИЯ О СТАТЬЕ. Дата поступления 17 декабря 2016 г.; дата принятия к печати 11 января 2017 г.; дата онлайн-размещения 31 марта 2017 г.
\end{abstract}

E. A. Reprintseva

Kursk State University, Kursk, Russian Federation

A. V. Galich

Kursk State University, Kursk, Russian Federation

\section{PSYCHO-EDUCATIONAL SUPPORT FOR FAMILIES UPBRINGING PRE-SCHOOL CHILDREN WITH RETARDATION OF PSYCHOLOGICAL DEVELOPMENT}

ABSTRACT. The study reflects the results of analyzing psychological and pedagogical literature on psycho-pedagogical support for families upbringing pre-school children with psychological development retardation. The article notes topicality of the problem stated in the context of increasing the number of children with psychological development retardation and inability of parents to build relationships with their

\section{Baikal Research Journal}


own children. It determined the range of problems faced by parents upbringing preschool children with psychological development retardation. It considers approaches to implementing psycho-pedagogical support for families upbringing pre-school children with psychological development retardation. The features of parent-child relationships in families raising a child with mental retardation. It describes the features of child-parent relations in the families upbringing pre-school children with psychological development retardation. It gives characteristics of diagnostic results for child-parent relations, systemizes general, particular and single problems of child-parent relations in the families upbringing a child with psychological development retardation. It specifies the main directions of the school teacher-psychologist's work in implementing psycho-pedagogical support for families upbringing a pre-school child with psychological development retardation. It presents a draft program of psycho-pedagogical support for families upbringing a pre-school child with psychological development retardation

KEYWORDS. Psycho-educational support; family; a child with psychological development retardation; directions of the school teacher-psychologist's work.

ARTICLE INFO. Received December 17, 2016; accepted January 11, 2017; available online March 31, 2017.

Постановка проблемы. Дошкольный возраст представляет собой предмет пристального внимания у многих ученых как важный и ответственный этап в жизни человека, как момент зарождения личности [1-5]. В это время происходит быстрое развитие всех психических процессов и личностных свойств. Ребенок начинает активно осваивать различные виды деятельности. В период дошкольного детства формируется самосознание и самооценка ребенка, происходит выстраивание мотивационной иерархии. В данный момент особое значение имеет влияние семьи на психическое развитие ребенка, а также воздействие существующей внутрисемейной системы детско-родительских отношений [6].

Семейное воспитание, межличностные отношения детей и родителей накладывают большой отпечаток на будущее ребенка. Психологи не раз обращали внимание на важность изучения семей, имеющих детей с задержкой психического развития (ЗПР).

Анализ исследований. Изучение проблемы взаимоотношений детей и родителей является чрезвычайно важной как для понимания факторов, которые непосредственно влияют на личностное становление детского организма, так и для организации психолого-педагогической практики в целом. Значимость данной проблемы подчеркивается во многих психологических теориях, таких как бихевиоризма, психоанализ и гуманистическая психология. В своих работах они рассматривали детско-родительские отношения как важный элемент в процессе детского развития [7].

В отечественной психологии вопросы семейного воспитания рассматривались Л. И. Божович, Л. С. Выготский, А. В. Запорожцем, О. А. Карабановой, А. Г. Лидерс, А. С. Спиваковской и др. Интерес современных психологов, таких как Э. Арутюнянц, Е. И. Захарова, И. М. Марковская, Н. А. Рождественская, Н. Ю. Синягина, Е. О. Смирнова, А. З. Шапиро, Э. Г. Эйдемиллер к проблеме отношений детей и родителей объясняется тем, что для детского развития особую значимость представляет взрослый. На отношениях между детьми и родителями сказываются тип семьи, стили отношений, позиция взрослых и та роль, которую занимает ребенок в семье. Под влиянием типа родительских отношений формируется личность ребенка [8].

Современными исследователями выявлено, что в семьях, которые воспитывают детей с ЗПР, проявляется ряд проблем, таких как: «нестабильность стиля воспитания», «отсутствие наказания», «ограниченность в применении требований -

\section{Baikal Research Journal}

электронный научный журнал Байкальского государственного университета 
обязанностей», «ограниченность в применении требований - запретов». В таких семьях существует взаимная связь между стилями родительского воспитания и показателями степени развития эмоционально-личностной сферы детей, также уровнем эмоциональной привязанности ребенка к родителю [9].

По мнению А. Н. Леонтьева, А. В. Петровского и других отечественных психологов, личностное развитие ребенка обусловлено эмоциональным контактом и особенностями взаимоотношений с родителями. Как указывает Т. А. Попова, тревожность и эмоционально-личностные установки дошкольника связаны со стилями отношения родителей [10]. При этом характер отношений с ребенком в семье взаимосвязан со смыслом жизни родителя [10]. Исходя из этого, выделяется проблема особенностей эмоционально-личностного общения в семьях, воспитывающих детей с ЗПР.

Задачи статьи. Охарактеризовать основные направления деятельности педагога-психолога по организации психолого-педагогического сопровождения семей, воспитывающих детей дошкольного возраста с задержкой психического развития; представить проект программы психолого-педагогического сопровождения семей, воспитывающих детей дошкольного возраста с задержкой психического развития.

Изложение основного материала. Анализ проблемы детско-родительских отношений в семьях, воспитывающих детей с задержкой психического развития, в современных психолого-педагогических исследованиях позволил сделать следующие выводы:

1. По сравнению с детьми дошкольного возраста с нормальным психическим развитием у дошкольников с ЗПР наблюдается низкий уровень эмоциональной идентификации, менее дифференцированная сфера социальных эмоций, высокий уровень самооценки, высокая эмоциональная привязанность к родителям.

2. Детско-родительские отношения дошкольников с задержкой психического развития характеризуются недостаточностью применения требований к ребенку.

3. Существует связь между стилями родительского воспитания, в семьях с ребенком с ЗПР, и такими показателями эмоционально-личностной сферы ребенка с задержкой развития, как идентификация, анализ эмоций и эмоциональная привязанность к родителям [6].

Позиция ребенка зависит не только от характера взаимоотношений с матерью, но и с другими близкими родственниками (сестра, брат). От них может потребоваться больше помощи маме по дому или же присматривать за ребенком с ЗПР, что ведет к ограничению контактов с другими детьми. Здоровые дети могут почувствовать, что их желания теперь соотносятся с потребностями особого члена семьи [11].

Квалифицированную помощь родителям в преодолении проблем в отношении с ребенком может оказать педагог-психолог.

Основной задачей психолога в работе с семьями, воспитывающими ребенка с ЗПР, является корректное и адекватное особенностям семьи психолого-педагогическое сопровождение. Основными направлениями деятельности психолога в рамках психолого-педагогического сопровождения являются: коррекционно-педагогическая и диагностико-консультационная работа.

В рамках коррекционно-педагогической деятельности психолог решает следующие задачи: выявление и коррекция отклонений в рамках детско-родительских отношений; разработка на основе диагностики коррекционной программы детско-родительских взаимоотношений; повышение у родителей уровня психологической грамотности, знаний о закономерностях развития ребенка, об основах воспитания; формирование у родителей навыков сотрудничества с ребенком и приемов коррекционно-воспитательной работы с ним; формирование умения по-

\section{Baikal Research Journal}


нимать и принимать ребенка таким, каков он есть через совместную деятельность детей и родителей.

Важную роль в коррекции детско-родительских отношений в семьях, воспитывающих ребенка с ЗПР, играет диагностико-консультационная деятельность психолога, которая предполагает: психолого-педагогическое изучение особенностей детско-родительских отношений в семьях, воспитывающих детей с задержкой развития; консультирование семей с детьми ЗПР по вопросам образования, развития, семейного воспитания и социальной адаптации; формирование общей культуры положительного семейного воспитания и взаимоотношений в целом [12].

На основе выявленных проблем, в ходе анализа детско-родительских отношений в семьях, воспитывающих детей с ЗПР, нами было проведено исследование состояния обозначенных отношений с дальнейшим составлением программы психолого-педагогического сопровождения этих семей.

Для исследования родительского отношения к ребенку с ЗПР дошкольного возраста применялась диагностика родительского отношения А. Я. Варги и В. В. Столина, для изучения восприятия членов семьи друг другом - тест «Семейная социограмма», для изучения внутрисемейных отношений со стороны ребенка применялся рисуночный тест «Моя семья».

Диагностика проводилась на основе изучения социально-личностных особенностей детей и их родителей, для чего использовались разнообразные методы и приемы: наблюдение, беседа с родителями, тестирование, сбор анкетных данных, опросники, проективные рисуночные тесты, анализ результатов.

Для выявления детско-родительских отношений в семьях, воспитывающих детей дошкольного возраста с ЗПР, были поставлены следующие задачи:

1. Проанализировать методы изучения детско-родительских отношений и разработать методику, структуру и содержание эксперимента.

2. Организовать и провести исследование детско-родительских отношений.

3. Провести анализ результатов исследования.

4. Выявить особенности детско-родительских отношений в семьях, воспитывающих детей с ЗПР дошкольного возраста.

5. Разработать программу коррекции детско-родительских отношений в семьях, воспитывающих детей с ЗПР дошкольного возраста методом игротерапии.

В эксперименте приняли участие пять семей, воспитывающих детей с ЗПР.

Перед проведением эксперимента нами был осуществлен сбор анамнестических сведений о развитии каждого ребенка: исследовалась психолого-педагогическая и медицинская документация детей, чьи родители приняли участие в экспериментальном исследовании.

Из пяти семей, воспитывающих детей с ЗПР:

- все семьи полные;

- возраст родителей колеблется от 25 до 36 лет;

- три семьи имеют два ребенка, у двух семей один ребенок;

- образование: высшее - три человека, среднее профессиональное - семь человек;

- из десяти человек восемь работают, двое - безработные;

- брак длится от $\mathbf{5}$ до 10 лет, две семьи имеют повторный брак;

- типы семей можно определить как:

- неблагополучных семей (пьющие родители) - три,

- проблемных семей (конфликтные ситуации в семье) - четыре,

- две семьи имеют неблагоприятные материальные и жилищные условия;

- жилищные условия: все семьи живут в благоустроенны квартирах.

\section{Baikal Research Journal}


Вся информация социологического характера была собрана при помощи социологических анкет, а также в процессе индивидуальной беседы с родителями. С целью диагностики детско-родительских отношений в семьях, воспитывающих детей дошкольного возраста с ЗПР, мы провели исследование с помощью методики «Тест-опросник родительского отношения».

Тест-опросник родительского отношения (ОРО) представляет собой психодиагностический инструмент, ориентированный на выявление родительского отношения у лиц, обращающихся за психологической помощью по вопросам воспитания детей и общения с ними.

Родительское отношение понимается как система разнообразных чувств по отношению к ребенку, поведенческих стереотипов, практикуемых в общении с ним, особенностей восприятия и понимания характера и личности ребенка, его поступков.

По результатам диагностики мам мы выявили, что такой тип отношения как симбиоз и кооперация проявляется у двух мам, отвержение - у одной мамы, инфантилизация - у двух мам, авторитарная гиперсоциализация - у двух мам.

По результатам диагностики пап мы обнаружили, что такой тип отношения как симбиоз проявил - один папа, инфантилизация - три папы, авторитарная гиперсоциализация - три папы, явление отвержения нами не выявлено.

Полученные данные позволяют сделать вывод, что в семьях отчетливо проявляется авторитаризм, родители требуют от детей безоговорочного послушания и дисциплины, навязывают им почти во всем свою волю. Также родители считают своих детей маленькими неудачниками. Интересы, увлечения, мысли и чувства детей кажутся взрослым несерьезными, и они игнорируют их. А у некоторых мам еще присутствует сильная симбиотическая связь. Данные, выявленные в ходе диагностики, были подтверждены и признаны самими родителями. В беседах с ними нами не раз встречались такие формулировки:

1. «Мой ребенок еще ничего не понимает, он же маленький» .

2. «Я - родитель, я знаю лучше».

3. «Это просто его дурное увлечение, повзрослеет - спасибо скажет».

Для выявления положения субъектов в системе межличностных отношений и определения характера коммуникаций в семье нами был использован тест «Семейная социограмма» (Э. Г. Эйдемиллер, О. В. Черемисин).

Данная проективная методика дает возможность отображения неосознаваемого контекста взаимоотношений между членами семьи, что делает ее эффективным инструментом семейной диагностики, консультирования и психотерапии.

Сравнивая результаты двух проведенных методик, мы обнаружили, что основными проблемами в отношениях родителей к детям являются:

1. Чрезмерное проявление авторитаризма.

2. Наличие сильной симбиотической связи.

3. Эмоциональное отвержение от детей.

Такая ситуация не может не сказываться на атмосфере в семье и на развитии ребенка.

Чтобы выявить положение субъекта в системе межличностных отношений и определить характер коммуникаций в семье со стороны ребенка мы использовали метод рисуночного теста «Моя семья».

Данная проективная методика дает возможность проследить особенности взаимоотношений между членами семьи, что делает ее эффективным инструментом семейной диагностики, консультирования и психотерапии.

Исследование рисунков детей показало преобладающую тревожность в семейных отношениях, конфликтность, отрешенность. Дети во многих случаях часто

\section{Baikal Research Journal}


стирали и перерисовывали, забывали нарисовать какую-нибудь часть тела или лица. Во многих рисунках они «отгораживали» себя от членов семьи, с которыми конфликтуют. В таких ситуациях явно выступают отношения отдаленности, отчужденности детей от родителей.

Изображение на рисунке себя непропорционально маленького, неподвижного или отсутствие «Образа - я» свидетельствует о переживании ребенком чувства неполноценности в семье, его депрессивности.

Анализ исследования рисунков семьи подтверждает тот факт, что в большинстве семей характер взаимоотношений вызывает у детей тревожность и конфликтность с членами семьи. Родители не способны справляться с возрастными проблемами психического и личностного развития детей. Возникает ощущение, что родители настойчиво стремятся «создать» идеальный образ ребенка, проявляя при этом излишнюю требовательность и нетерпимость, завышенный уровень притязаний в отношении возможностей детей.

На основании полученных данных в ходе исследования детско-родительских отношений в семьях, воспитывающих детей с ЗПР дошкольного возраста можно выделить наличие таких проблем:

1. Общие проблемы:

- чрезмерное проявление авторитаризма;

- наличие сильной симбиотической связи;

- эмоциональное отвержение от детей.

2. Особенные проблемы:

- отсутствие понимания у родителей значения собственного поведения и своих чувств для ребенка;

- неадекватное восприятие собственного ребенка;

3. Единичные проблемы: незнание особенностей развития личности дошкольника и причин возможных отклонений в поведении.

Итак, родители являются наиболее значимыми людьми для своих детей, особенно в те годы, когда еще только формируется личность ребенка. Анализ психолого-педагогических исследований по вопросам семейного воспитания свидетельствует о том, что в распоряжении родителей всегда находилась более чем достаточная информация по вопросам воспитания детей и другим, семейным проблемам.

В ходе диагностического исследования, мы выявили, что особенности нарушения во взаимоотношениях «родитель - ребенок» связаны, главным образом, с неэффективными способами общения и поведения родителей во взаимодействии с детьми.

На основе результатов психодиагностической работы нами была составлена программа коррекции детско-родительских отношений в семьях, воспитывающих детей с ЗПР дошкольного возраста на основе метода игротерапии.

Цель программы - формирование навыков гармоничного, позитивного взаимодействия родителей с детьми.

Задачи программы:

- актуализация потребности к освоению навыков позитивного взаимодействия родителя с ребенком;

- повышение педагогической компетентности у родителей;

- формирование конструктивного стиля взаимодействия родителя с ребенком;

- гармонизация детско-родительских отношений.

Предполагаемый результат:

- осознание положительной родительской позиции, выявление негативных установок;

- повышение педагогической компетентности у родителей;

\section{Baikal Research Journal}


- овладение стилем конструктивного взаимодействия в конфликтных ситуациях в семейных отношения;

- «безусловное принятие» родителем ребенка.

Основной метод групповой психотерапии - игротерапия.

Вспомогательные методы: беседы, самодиагностика, сказкотерапия, музыкотерапия, куклотерапия.

Режим занятий: программа проводится в групповой форме, наполнение группы 8-10 родителей. Программа рассчитана на 12 часов, 8 занятий по 45 минут каждое.

Формы контроля результативности занятий - результативность программы определяется при сравнении результатов исходящей и заключительной диагностики методами:

- PARI. Тест-опросник изучения родительских установок, Е. С. Шефер и Р. К. Белл.

- тест «Семейная социограмма» (Э. Г. Эйдемиллер, О. В. Черемисин).

Место проведения: кабинет школьного педагога-психолога, актовый зал.

Структура коррекционно-обучающей программы. Программа включает три основных блока, различающихся по своим задачам и продолжительности:

- I этап - ориентировочный (1 занятие) - направлен на знакомство членов группы, их объединение и на актуализацию потребности у родителей к освоению навыков позитивного взаимодействия с ребенком;

- II этап - обучающий (2 занятия) - направлен на актуализацию потребности у родителей к освоению навыков позитивного взаимодействия с ребенком, а также на повышение родительской педагогической компетентности;

- III этап - терапевтический (4 занятия) - направлен на формирование конструктивного стиля взаимодействия родителя с ребенком и гармонизацию детско-родительских отношений.

В начале и в конце цикла занятий работа направлена на занятия с родителями с целью диагностики и коррекции нарушений детско-родительских взаимоотношений. В середине цикла занятия рассчитаны на совместную деятельность детей и их родителей, и направлены они на формирование конструктивного стиля взаимодействия родителя с ребенком, гармонизацию детско-родительских отношений.

Результатом программы должно стать:

- построение каждым участником определенной модели оптимальных взаимоотношений с детьми, позволяющей расширить и укрепить позитивные контакты родителей с детьми путем повышения их сензитивности к детским переживаниям;

- приобщения родителей к базовым знаниям о потребностях и поведении детей;

- развития навыков коммуникации в процессе межличностного общения.

Выводы. Подводя итог результатам исследования детско-родительских отношений можно отметить, что большинство родителей проявляют неадекватный тип отношений к ребенку. Они воспринимают своего ребенка как плохого, неприспособленного, неудачливого человека. И именно такое отношение родителей к ребенку, приводит к появлению у последнего отрицательных эмоций в отношении семьи, окружающих, тревожности, агрессии и прочих проблем в развитии. В данном случае семья нуждается в адекватной помощи психолога.

\section{Список использованной литературы}

1. Адлер А. Воспитание детей. Взаимодействие полов : пер с англ. / А. Адлер. - Ростов н/Д. : Феникс, 2008. - 448 с.

2. Акатов Л. И. Социальная реабилитация детей с ограниченными возможностями здоровья: психологические основы : учеб. пособие / Л. И. Акатов. - М. : ВЛАДОС, 2003. - 368 с.

\section{Baikal Research Journal}


3. Божович Л. И. Этапы формирования личности в онтогенезе // Проблемы формирования личности. Избранные психологические труды / Л. И. Божович. - М. : Просвещение, 2002. - C. 193-228.

4. Большаков В. Ю. Психотренинг. Социодинамика, игры, упражнения / В. Ю. Большаков. - СПб. : Речь, 2006. - 384 с.

5. Гарбузов В. И. Воспитание ребенка в семье: советы психотерапевта / В. И. Гарбузов. - СПб. : КАРО, 2006. - 296 с.

6. Ильин Е. П. Эмоции и чувства / Е. П. Ильин. - СПб. : Питер, 2001. - 752 с.

7. Рождественская Н. А. Негармоничные стили семейного воспитания и восприятия родителями своих детей / Н. А. Рождественская, А. В. Разумова // Вестник Московского университета. Сер. 14, Психология. - 2002. - № 2. - С. 48-55.

8. История зарубежной дошкольной педагогики : хрестоматия : учеб. пособие / сост. Н. Б. Мчедлидзе, А. А. Лебеденко, Е. А. Гребенщикова. - 2-е изд., доп. - М. : Просвещение, 1986. - 464 с.

9. Карелина И. О. Проблема понимания эмоций детьми дошкольного возраста / И. О. Карелина // Ярославский педагогический вестник. - 2010. - Т. 2, № 4. - С. 241-247.

10. Попова Т. А. Взаимосвязь детско-родительских отношений и тревожности дошкольника / Т. А. Попова, С. Сулейманова // Фундаментальные исследования. 2012. - № 11-5. - C. 1145-1148.

11. Иванова Н. В. Формирование социального пространства отношений ребенка в дошкольном образовательном учреждении : учеб. пособие / Н. В. Иванова. - Череповец : Череповец. гос. ун-т, 2002. - 150 с.

12. Гозман Л. Я. Социально-психологические исследования семьи: проблемы и перспективы / Л. Я. Гозман, Ю. Е. Алешина // Психологический журнал. — 2001. — № 2. C. $20-22$.

\section{References}

1. Adler Alfred. The Education of Children. South Bend, Indiana: Gateway Editions, Ltd., 1978. (Russ. ed.: Adler Alfred. Vospitanie detei. Vzaimodeistvie polov. Rostov-on-Don, Feniks Publ., 2008. 448 p.).

2. Akatov L. I. Sotsialnaya reabilitatsiya detei s ogranichennymi vozmozhnostyami zdorovya: psikhologicheskie osnovy [Social Rehabilitation of Children with Disabilities: Psychological Basic Concepts]. Moscow, VLADOS Publ., 2003. 368 p.

3. Bozhovich L. I. Stages of personality formation in ontogenesis. In Bozhovich L. I. Problemy formirovaniya lichnosti. Izbrannye psikhologicheskie trudy [Problems of personality formation. Selected psychological works]. Moscow, Prosveshchenie Publ., 2002, pp. 193-228. (In Russian).

4. Bolshakov V. Yu. Psikhotrening. Sotsiodinamika, igry, uprazhneniya [Psycho-training. Sociodynamics, games, exercises]. Saint Petersburg, Rech' Publ., 2006. 384 p.

5. Garbuzov V. I. Vospitanie rebenka $v$ sem'e: sovety psikhoterapevta [Upbringing a child in family: psychotherapist's advice]. Saint Petersburg, KARO Publ., 2006. 296 p.

6. Ilyin E. P. Emotsii $i$ chuvstva [Emotions and Feelings]. Saint Petersburg, Piter Publ., 2001. $752 \mathrm{p}$.

7. Rozhdestvenskaya N. A., Razumova A. V. Inharmonic styles of family education and parents' perception of their children. Vestnik Moskovskogo universiteta. Seriya 14, Psikhologiya = Moscow University Bulletin. Series 14, Psychology, 2002, no. 2, pp. 48-55. (In Russian).

8. Mchedlidze N. B., Lebedenko A. A., Grebenshchikova E. A. (eds). Istoriya zarubezhnoi doshkol'noi pedagogiki [History of foreign pre-school pedagogics]. $2^{\text {nd }}$ ed. Moscow, Prosveshchenie Publ., 1986. 464 p.

9. Karelina I. O. Problem of understanding emotions by pre-school children. Yaroslavskii pedagogicheskii vestnik = Yaroslavl Pedagogical Bulletin, 2010, vol. 2, no. 4, pp. 241-247. (In Russian).

10. Popova T. A., Suleimanova S. Interconnection of parent-child relations and pre-school child's anxiety. Fundamental'nye issledovaniya = Fundamental Investigations, 2012, no. 11-5, pp. 1145-1148. (In Russian).

11. Ivanova N. V. Formirovanie sotsial'nogo prostranstva otnoshenii rebenka $v$ doshkol'nom obrazovatel'nom uchrezhdenii [Developing social space of child's relations in pre-school educational institution]. Cherepovets State University Publ., 2002. 150 p.

\section{Baikal Research Journal}


12. Gozman L. Ya., Aleshina Yu. E. Socio-psychological investigation of family: problems and prospects. Psikhologicheskii zhurnal = Psychology Journal, 2001, no. 2, pp. 20-22. (In Russian).

\section{Информация об авторах}

Репринцева Елена Алексеевна - доктор педагогических наук, профессор, профессор кафедры коррекционной психологии и педагогики, Курский государственный университет, 305000, Курск, ул. Радищева, 33, e-mail: lab.game@mail.ru.

Галич Анастасия Владилировна - студент 4-го курса дефектологического факультета, Курский государственный университет, 305000, Курск, ул. Радищева, 33, e-mail: nastena-suta@mail.ru.

\section{Authors}

Elena A. Reprintseva - Doctor habil. (Pedagogics), Professor, Chair of Correctional Psychology and Pedagogics, Kursk State University, 33 Radishchev St., 305000, Kursk, Russian Federation; e-mail: lab.game@mail.ru.

Anastasiya $V$. Galich $-4^{\text {th }}$-Year Student of Defectological Faculty, Kursk State University, 33 Radishchev St., 305000, Kursk, Russian Federation; e-mail: nastena-suta@mail.ru.

\section{Библиографическое описание статьи}

Репринцева Е. А. Психолого-педагогическое сопровождение семей, воспитывающих детей с задержкой психического развития дошкольного возраста / Е. А. Репринцева, A. В. Галич // Baikal Research Journal. - 2017. - T. 8, № 1. — DOI: 10.17150/24116262.2017.8(1).29.

\section{Reference to article}

Reprintseva E. A., Galich A. V. Psycho-educational support for families upbringing preschool children with retardation of psychological development. Baikal Research Journal, 2017, vol. 8, no. 1. DOI: 10.17150/2411-6262.2017.8(1).29. (In Russian).

\section{Baikal Research Journal}

